\title{
reversed, mirrored, selfie
}

\section{Madeleine Lychek}

Madeleine Lychek is a queer Filipino-Canadian

interdisciplinary artist. She uses performance, video, digital media, drawing and printmaking to explore her intersectional identity and prioritizes experimentation, process, and conceptual thought over end result.

Lychek completed her Honours BA in Studio Art at the University of Guelph and is currently the Digital Education Coordinator at Ed Video Media Arts Centre. 


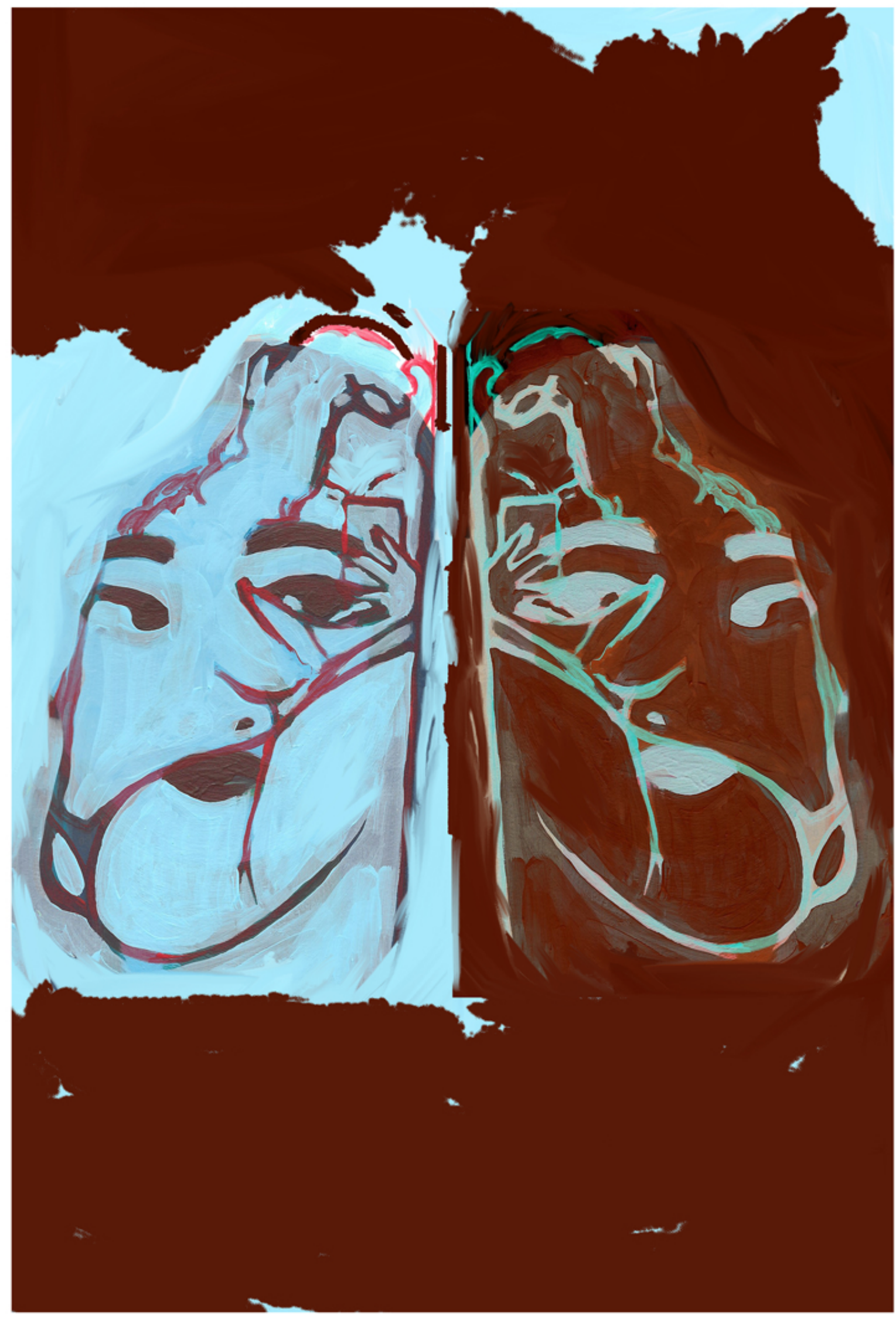

in:cite journal vol. 4 